\title{
Divisive Gain Modulation of Motoneurons by Inhibition Optimizes Muscular Control
}

\author{
(D)Mikkel Vestergaard and $\odot$ Rune W. Berg \\ Faculty of Health and Medical Sciences, Department of Neuroscience and Pharmacology, University of Copenhagen, 2200 Copenhagen, Denmark
}

When using muscles, the precision with which force is delivered is as important as the delivery of force itself. Force is regulated by both the number of recruited motoneurons and their spike frequency. While it is known that the recruitment is ordered to reduce variability in force, it remains unclear whether the motoneuron gain, i.e., the slope of the transformation between synaptic input and spiking output, is also modulated to reduce variability in force. To address this issue, we use turtle hindlimb scratching as a model for fine motor control, since this behavior involves precise limb movement to rub the location of somatic nuisance touch. We recorded intracellularly from motoneurons in a reduced preparation where the limbs were removed to increase mechanical stability and the motor nerve activity served as a surrogate for muscle force. We found that not only is the gain of motoneurons regulated on a subsecond timescale, it is also adjusted to minimize variability. The modulation is likely achieved via an expansive nonlinearity between spike rate and membrane potential with inhibition having a divisive influence. These findings reveal a versatile mechanism of modulating neuronal sensitivity and suggest that such modulation is fundamentally linked to optimization.

Key words: control; divisive; gain; inhibition; motoneuron; optimal

\section{Introduction}

The nervous system has a remarkable ability to adapt to different situations covering a large dynamic range (Carandini and Heeger, 2012). In the motor system, there are often only few motoneurons available to control muscle contraction from twitches to forceful movements. For instance, the human muscle medial gastrocnemius delivers tension from 0.63 to 203.5 g, i.e., a 300 -fold dynamic range accomplished by a mere few hundred motoneurons (Garnett et al., 1979). Motoneurons, which are outnumbered by interneurons 1:5 in turtles (Walløe et al., 2011), are scarce considering the task of covering this large dynamical range. Therefore, gain modulation of motoneurons could be beneficial, but whether it occurs on the appropriate timescale and in a manner that optimizes motor control is unknown.

Experiments suggest that variability of force is minimized (Jones et al., 2002) and an optimal control theory (Harris and Wolpert, 1998) suggests the variability in force during muscle contractions, $\Delta F$, scales with the force itself, $F$, such that the relative variability, $\Delta F / F$, is approximately constant. A similar optimization principle known as Weber's law is widespread in

\footnotetext{
Received Sept. 19, 2014; revised Jan. 8, 2015; accepted Jan. 15, 2015.

Author contributions: M.V. and R.W.B. designed research; M.V. and R.W.B. performed research; M.V. and R.W.B. analyzed data; M.V. and R.W.B. wrote the paper.

This work was supported by the Novo Nordisk Foundation (R.W.B.) and the Danish Council for Independent Research Medical Sciences (R.W.B. and M.V.). We thank Kristian Jensen, Robert Sachdev, Joshua Motelow, and Hanne Rasmussen for help with and advice on histology, which was performed at the Core Facility for Integrative Microscopy, University of Copenhagen; and Mickey London and John Hertz for useful comments on an earlier version of this manuscript.

The authors declare no competing financial interests.

Correspondence should be addressed to Rune W. Berg at the above address. E-mail: runeb@sund.ku.dk.

DOI:10.1523/JNEUROSCI.3899-14.2015

Copyright $\odot 2015$ the authors $\quad 0270-6474 / 15 / 353711-13 \$ 15.00 / 0$
}

sensory systems. Here, perceptual sensitivity is kept constant such that the "just noticeable difference" $(\Delta S)$ is proportional to absolute stimulus intensity $(S)$ and $\Delta S / S \approx$ constant. Weak stimuli can be differentiated better while still responding to strong stimuli (Hatze, 1979).

How is such optimization implemented in the motor system? The force is regulated both by the number of active motoneurons and by their spike frequency. Variance in force is minimized during recruitment by having an exponential increase of twitch force across motor units (Fig. 1a). The motor units are recruited in an orderly fashion from smallest to largest (Milner-Brown et al., 1973; Fig. 1b). This is known as the size principle (Henneman and Mendell, 1981; Mendell, 2005) and this allows adjustment of weak force more precisely than strong force while keeping the relative variability constant.

While sensory-motor processing is optimized according to the minimum-variance principle, it is not known whether force regulation by spike-rate modulation also follows this principle. We conjecture that if spike-rate modulation is participating in minimizing variance, then the gain, which scales the variability in spike rates, would be modulated in proportion to force (Fig. 1c). We tested this in motoneurons in turtles performing hindlimb scratching. A skin nuisance can elicit a specific motor pattern for the hindlimb to scratch the exact location. This requires fine motor control, especially during the rub phase (Mortin et al., 1985). The limbs were removed to ensure sufficient stability for intracellular recordings, though the somatosensory system was left intact. This allowed calculation of the spike-rate response to current input (RI function) and neuronal gain. We tested whether neuronal gain was modulated on subsecond timescales. Further, we investigated whether gain modulation enhances force control. Finally, we investigated mechanisms behind gain 
a

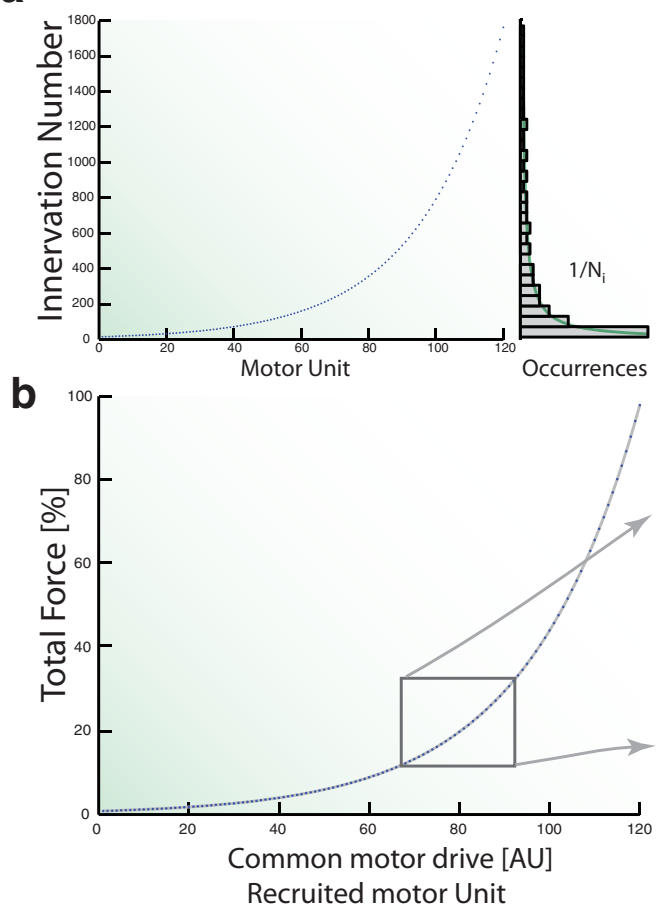

C

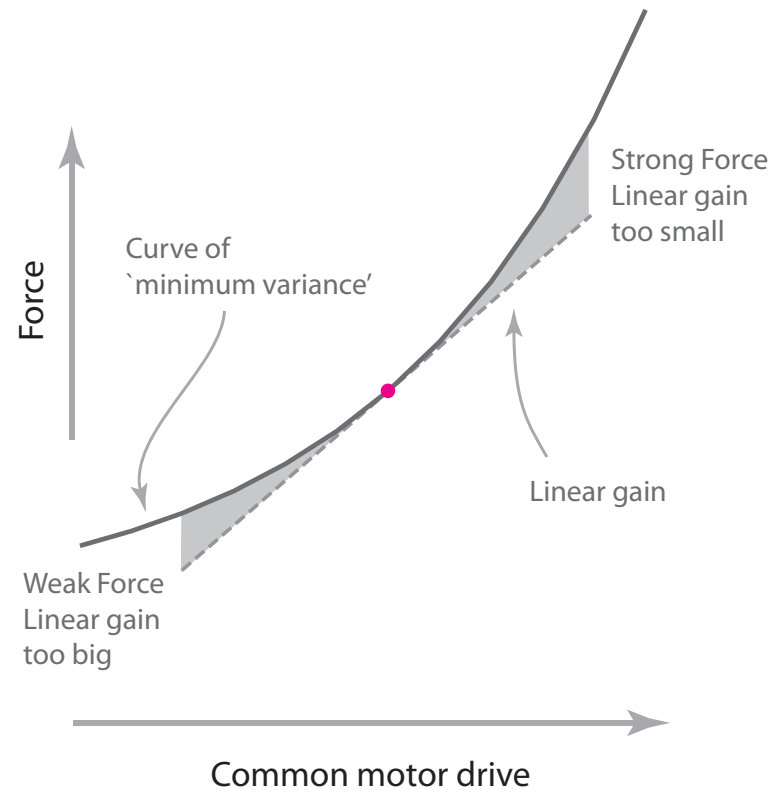

Figure 1. Ordered recruitment and gain modulation according to minimal variance principle. $a$, The innervation number, i.e., the number of muscle fibers a given motoneuron innervates (twitch force) in a typical muscle (human first dorsal interosseous muscle; Feinstein et al., 1955; Enoka and Fuglevand, 2001). Left, The innervation number is increasing exponentially with the ordered motoneuron number. Right, The distribution of innervation numbers among motor units. $\boldsymbol{b}$, The cumulative muscle force $(F)$ produced by an ordered recruitment is also exponentially shaped and the slope represents the variability in force $(\Delta F)$.c, A single motoneuron can regulate force around its mean activity (magenta dot) by changing its discharge rate. If the gain is linear (broken line), there is a growing mismatch between both the force (shaded area) and the gain, i.e., the slope, compared with the curve of minimum variance. This mismatch can be eliminated by adjusting gain such that gain $\propto$ force, which is the prediction of the present study.

modulation, especially the role of inhibition, since it has recently been implicated to be present on motoneurons during muscle contraction in both cats (Johnson et al., 2012) and turtles (Petersen et al., 2014).

\section{Materials and Methods}

Integrated preparation. Sixty-three adult red-eared turtles (Trachemys scripta elegans) of both sexes were used in this study. Each animal was placed on crushed ice for $2 \mathrm{~h}$ to ensure hypothermic anesthesia, then killed by decapitation and blood substituted by perfusion with a Ringer's solution containing the following (in mM): $120 \mathrm{NaCl}, 5 \mathrm{KCl}, 15 \mathrm{NaHCO}_{3}$, $2 \mathrm{MgCl}_{2}, 3 \mathrm{CaCl}_{2}$, and 20 glucose, saturated with $98 \% \mathrm{O}_{2}$ and $2 \% \mathrm{CO}_{2}, \mathrm{pH}$ 7.6. The carapace containing the $\mathrm{D} 4-\mathrm{D} 10$ spinal cord segments was isolated by transverse cuts as described previously (Alaburda and Hounsgaard, 2003; Alaburda et al., 2005) and the cord was perfused with Ringer's solution through the vertebral foramen via a steel tube and gasket pressing against the $\mathrm{D} 4$ vertebra. The surgical procedures comply with Danish legislation and were approved by the controlling body under the Ministry of Justice.

Electrophysiology. Each scratch episode lasted $\sim 20$ s. A new trial was initiated after a $5 \mathrm{~min}$ rest. Electroneurogram (ENG) recordings were performed with suction electrodes of the hip flexor nerve and dD8 at the level of D9-D10 vertebrae. The ENGs were recorded with a differential amplifier Iso-DAM8. The bandwidth was $300 \mathrm{~Hz}-1 \mathrm{kHz}$. The transverse cut was performed at the caudal end of D10 of the spinal cord to get access to the motoneurons. For most cells, intracellular recordings were made with sharp electrodes $(\approx 40-60 \mathrm{M} \Omega$ ) but for a subset of cells they were made with whole-cell patch electrodes $(\approx 6 \mathrm{M} \Omega)$. Sharp electrodes were filled with a mixture of $0.9 \mathrm{M}$ potassium acetate and $0.1 \mathrm{M} \mathrm{KCl}$. Patch electrodes were filled with the following (in $\mathrm{mM}$ ): $122 \mathrm{~K}$-gluconate, 5 $\mathrm{Na}_{2}$-ATP, $2.5 \mathrm{MgCl}_{2}, 300 \cdot 10^{-3} \mathrm{CaCl}_{2}, 5.6 \mathrm{Mg}$-gluconate hemi $\mathrm{Mg}$ salt, $5 \mathrm{~K}$-HEPES, $5 \mathrm{H}$-HEPES, $103 \mathrm{KOH}$, and 1 EGTA. In most experiments, the electrodes also contained 4\% w/v biocytin. All experiments were conducted in current-clamp mode with a Multiclamp 700B amplifier (Molecular Devices). Data were sampled at $10 \mathrm{kHz}$ with a 16 bit analogto-digital converter, controlled and displayed with Clampex software. Glass pipettes were pulled on a P-1000 (Sutter Instruments). Motoneurons were accessed from the surface at a typical depth of $50-300 \mu \mathrm{m}$.

Identification of motoneurons. Motoneurons were mainly identified by their location in the ventral horn, size (via $R_{\mathrm{m}}$ ), size of action potentials, and spiking relation with nerve activity. A subset was filled with biocytin for histological processing. The tissue containing the motoneuron was carefully removed and left in PBS with 4\% paraformaldehyde for 24-48 $h$. The tissue was then rinsed with and stored in PBS. The tissue section was mounted in an agar mount and sliced into several $100 \mu \mathrm{m}$ slices using a microtome (Leica, VT1000 S). The slices were incubated for 3-4 $\mathrm{h}$ at room temperature with cyanine-3 conjugated (Cy3) to streptavidin (1:500 or 1:250; Jackson ImmunoResearch) in blocking buffer (PBS with $5 \%$ donkey serum and $0.3 \%$ Triton X-100). The slices were washed with $\mathrm{PBS}$ and incubated overnight at $4^{\circ} \mathrm{C}$ with primary choline acetyltransferase (ChAT) antibodies and goat anti-ChAT antibodies (1:500; AB144P, Millipore) diluted in blocking buffer. The slice was washed three times with PBS and incubated for $1 \mathrm{~h}$ at room temperature with the secondary antibody Alexa488 conjugated to donkey anti-goat antibodies (1:1000; Jackson ImmunoResearch Laboratories) diluted in blocking buffer. After three washes with PBS, the slice was mounted and coverslipped using ProLongGold antifade reagent (Invitrogen) and cured overnight at room temperature before microscopy. Micrographs were produced using a confocal microscope, Zeiss LSM 700 with diode lasers, on a Zeiss Axiolmager M2 using a 20×/0.8 Apochromat objective (Zeiss). The fluorophores were excited/detected at the following: Cy3 at $555 \mathrm{~nm} /$ $559-700 \mathrm{~nm}$, Alexa488 at $488 \mathrm{~nm} / 405-544 \mathrm{~nm}$, and DAPI at 405/420$700 \mathrm{~nm}$. The pinhole was $35 \mu \mathrm{m}$, resulting in an optical section of $2 \mu \mathrm{m}$. For all the channels a $5 \times 6$ mosaic was made. During the $z$-stack of Cy3 
fluorescence, 15 optical slices with slight overlap gave a total optical section of $28 \mu \mathrm{m}$. A maximum-intensity projection of the Cy3 $z$-stack was done and superimposed on the DAPI and Alexa488 image. The DAPI and Alexa488 image was taken in the middle of the Cy3 $z$-stack. Images were handled with ZEN 2011 software (Zeiss) in the LSM and 8 bit TIFF format.

Evoking scratch-like behavior. To activate the scratching motor pattern, mechanical touch was applied to the carapace by a fire-polished tip of a bent glass rod mounted to the membrane of a loudspeaker (Alaburda et al., 2005). The stimulus was controlled by a function generator (TT2000, Thurlby Thandar Instrument) and the stimulus was given as a 10-s-long sinusoidal movement. Stimuli were applied on the border of the carapace marginal shields M9-M10 and the soft tissue surrounding the hindlimb. This area is the receptive field for pocket scratching (Mortin et al., 1985).

Data selection criteria. Some of the data (12 of 63 motoneurons) used in the present study have been part of previous published investigations, where they were analyzed in a different context for a different purpose (Berg et al., 2007, 2008). Out of the collected data, 25 neurons were used for the main analysis and seven were used for the strychnine experiments. Thirty-five cells recorded as part of the main study had to be discarded according to the following reasons. To perform the analysis, the scratch motor pattern had to contain $\geq 2$ cycles. The number of cycles varied from turtle to turtle and could also vary from trial to trial, but rarely with $>1$ cycle. These cycles had to have a larger variance between cycles than their variance across trials, such that any covariance among ENG recordings and gain could be established. If cycles had larger variance across than within trials, they were excluded from the analysis. This was typically the last cycle. The average number of removed cycles was 0.92 cycles per trial per animal. The total number of cycles per trial varied from 3 to 10 across animals and the average number of included cycles based on the above criteria per trial across animal was 5.7 cycles. The quantitative criteria for removing cycles from the trials are based on the rectified and filtered ENG peak-cycle values across and within trials, which we indicate $E N G_{i j}$. The indices refer to the $i$ th trial and $j$ th cycle. The mean for cycle $j$ is $\mu_{j}=\sum_{i=1}^{N} E N G_{i j} / N$, where $N$ is the total number of trials. Similarly, the mean cycle ENG for trial $i$ is $\mu_{i}=\sum_{j=1}^{K} E N G_{i j} / K$, where $K$ is the number of cycles. The trial variance of cycle $j, \sigma_{j}^{2}$, and the variance of $E N G$ across cycles averaged over trials, $\sigma_{c y c l e s}^{2}$, respectively are estimated as follows:

$$
\begin{gathered}
\sigma_{j}^{2}=\frac{1}{K} \sum_{i=1}^{K}\left(E N G_{i j}-\mu_{i}\right)^{2} \\
\sigma_{\text {cycles }}^{2}=\frac{1}{K N} \sum_{i=1}^{K} \sum_{j=1}^{N}\left(E N G_{i j}-\mu_{j}\right)^{2}
\end{gathered}
$$

For a cycle $j$ to be excluded from the analysis, the trial variance had to be larger than the variance in ENG within a trial, i.e., $\sigma_{j}^{2}>\sigma_{\text {cycles }}^{2}$ (see Fig. 3c).

In some preparations a covariance was not possible to detect either because too few recorded trials were available to establish statistics, or the network activity across trials was unstable, or the intracellular recording was prevented by electrode rectification and instability. These issues were often decided by the researcher during the experiment without rigorous quantification. Electrode impedance was typically 40-60 $\mathrm{M} \Omega$. In the strychnine experiments, some cells had to be discarded for the above reasons or because of insufficient response to strychnine application, likely depending on the depth-recording electrode and flow rates.

Strychnine experiments. Ringer's solution flowed from rostral toward caudal direction through the spinal canal of the animal, which was placed upside down so that the solution was flowing against gravity. A microtube was placed close to the cut surface to locally support the area with a different flow of Ringer's solution with phenol red dye for visual inspection. Once the experiment was ready, strychnine (strychnine hydrochloride, Sigma-Aldrich) was added to this second flow $(10 \mu \mathrm{M})$, thus only affecting a few cells on the surface where the intracellular recording electrode was placed. Datasets where strychnine was applied were selected based on the effect on the membrane potentials $\left(V_{\mathrm{m}} \mathrm{s}\right)$ following the application. If the presence of clear IPSPs vanished or the distribution of
$V_{\mathrm{m}}$ had a depolarizing shift following the application of strychnine, the data were included in the population. If there was no such effect, the recorded cell was assumed to be too deep below the surface for the superfusion medium to reach, and the data were excluded.

Data processing. All estimation and data processing was done in Matlab (version 2012b, Mathworks). All correlation coefficients were calculated as Pearson product moment correlation coefficients. The linear fits (see Figs. 2, 4-6) were generic least square fits performed with Matlab procedures, including their $95 \%$ confidence limits (see Figs. $2 d, 4 d, e$ ). When correlating the gain with the mean $V_{\mathrm{m}}$ (see Fig. $5 a, b$ ), which was averaged over a $200 \mathrm{~ms}$ time window around the peak $V_{\mathrm{m}}$, some cells could be hyperpolarized enough to avoid spikes. For the cells that could not be hyperpolarized enough, spikes were instead removed from the trace as a compromise, for which the mean was estimated. The spikes were removed $2 \mathrm{~ms}$ before and $15 \mathrm{~ms}$ after the spike peak. To determine whether there was a significant increase in slope and intercept following strychnine application (see Figs. 8, 9), binomial statistics were applied. The cycles and cells were classified as having either a decrease or an increase (above or below the unity line) such that the population revealed an increase/decrease (Berg et al., 2008). If no effect were present, the observations (before vs after strychnine) should have equal probability ( $p=$ 0.5 ) of being above or below the unity line. Therefore, the mean value of the fraction of increase should be at 50\% (see Figs. 8, 9) with an SE given by Berg et al. (2008) as follows:

$$
S E=\sqrt{p \cdot(1-p) / k}=\sqrt{0.25 / k}
$$

where $k$ is the number of observations. The $95 \%$ confidence limits are then $\pm 1.96 \cdot$ SE.

Spike-rate estimation and ENG filtering. The time-dependent firing rate was estimated by kernel estimation. First the spikes were identified by threshold. The exact time was defined to be the peak of the spike. A kernel $k(t)$ was convolved with the spike times $x(t)$ to estimate the firing rate as a function of time as follows:

$$
\operatorname{rate}(t)=\int_{-\infty}^{\infty} x\left(t-t^{\prime}\right) k\left(t^{\prime}\right) d t^{\prime}
$$

We used the Gaussian kernel as follows:

$$
k(t)=\frac{1}{\sqrt{2 \pi} w} e^{-\frac{t^{2}}{2 w^{2}}}
$$

with a bandwidth $w=40 \mathrm{~ms}$, except in Figure 5, where it was $w=50 \mathrm{~ms}$. The same kernel was used to characterize the ENG activity, where the measured nerve signal was rectified and filtered using the Gaussian kernel with a bandwidth of $w=75 \mathrm{~ms}$.

Spike intensity versus $V_{\mathrm{m}}$. The metric we use for estimating the spike intensity as a function of $V_{\mathrm{m}}$ is the following. First we empirically determined the $V_{\mathrm{m}}$ distribution before the spike (1.5-1.7 ms prior). Then we normalized this distribution with the total amount of time spent at each $V_{\mathrm{m}}$ value. This is the probability of getting a spike within a small time window for a given $V_{\mathrm{m}}$. This is defined as the spike intensity as a function of $V_{\mathrm{m}}$ (Jahn et al., 2011), analogous to intensity of a Poisson process, and is approximately the spike rate when the spiking can be considered a renewal process. The shape of the spike intensity is highly nonlinear with upward curvature. This is often referred to as expansive nonlinearity (Hansel and van Vreeswijk, 2002; Miller and Troyer, 2002; Murphy and Miller, 2003). An exponential $R\left(V_{m}\right)=c e^{\beta V_{m}}$ was fitted to capture the curvature, where the curvature is represented in the exponent $\beta$, which have units of $1 / \mathrm{mV}$, and $c$ is a constant of units $1 / \mathrm{s}$. Such expansive nonlinearities have also been investigated in the visual cortex, where they are often characterized as a power-law relationship, i.e., $R\left(V_{m}\right)=k\left[V_{m}-E_{a}\right]^{\alpha}$, where $\alpha$ is the scaling parameter, often ranging from two to five (Hansel and van Vreeswijk, 2002; Miller and Troyer, 2002). This exponent is also a measure of the expansive curvature of the nonlinearity. We also fitted a power law to the spike intensity for comparison (see Fig. $6 B, C$ ). The question of whether a power-law fit is better than an exponential (Jahn et al., 2011) is difficult to answer, since 

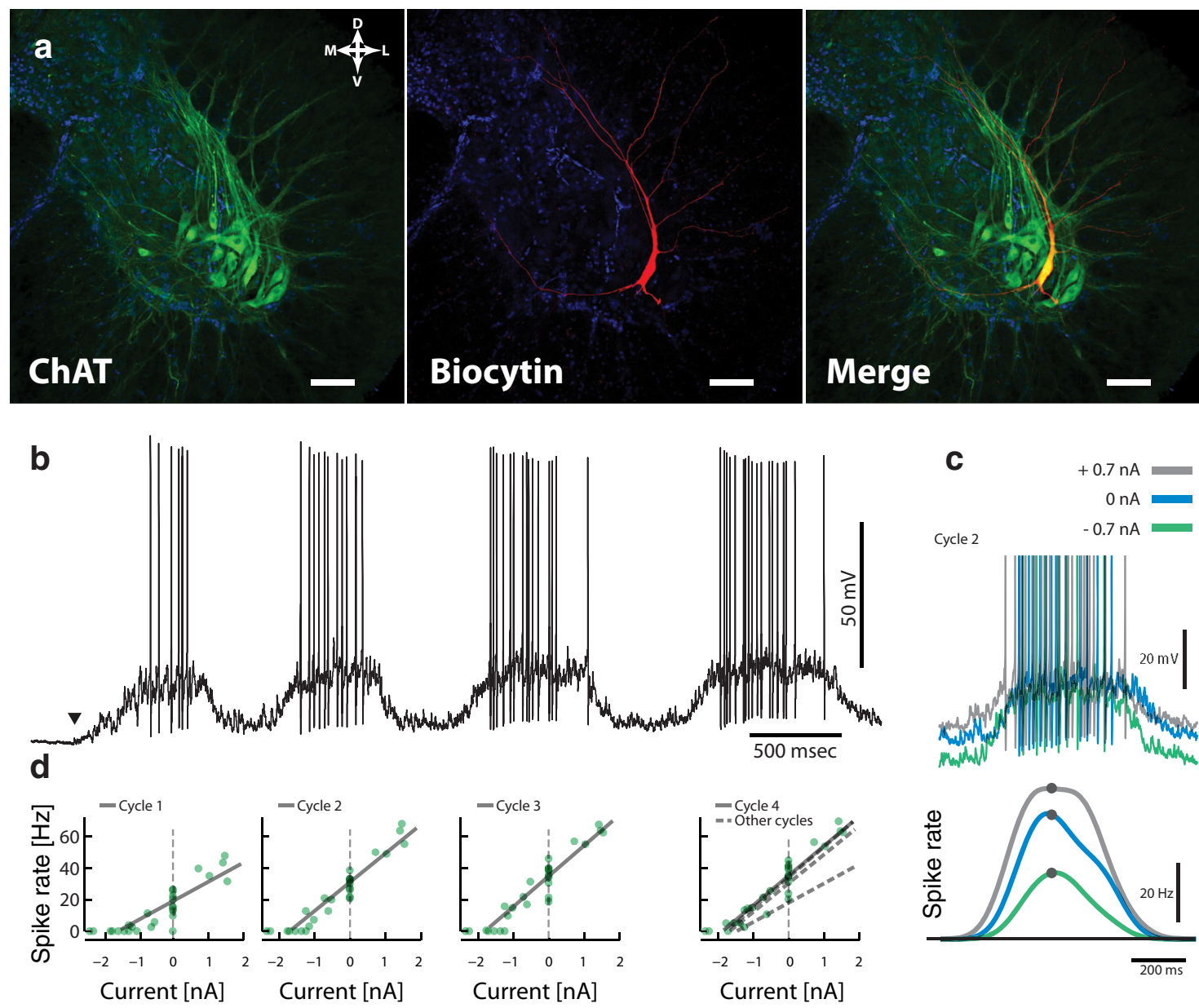

e

f
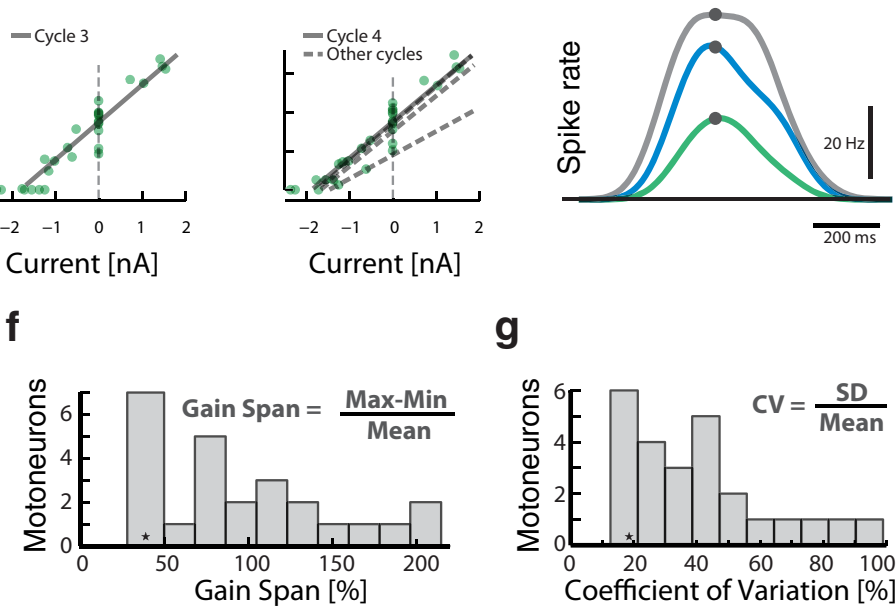

g
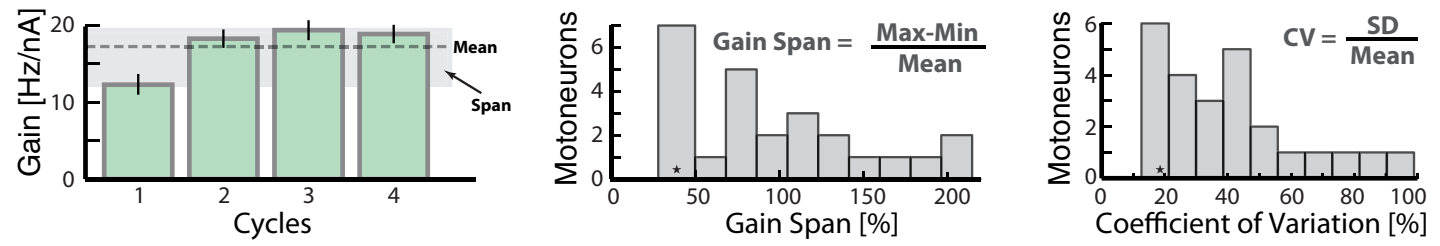

Figure 2. Gain of motoneurons is modulated during behavior. $\boldsymbol{a}$, Histological verification that recorded neuron (red fluorescent biocytin) is a spinal motoneuron (green, ChAT) in the ventral horn (scale bars, $100 \mu \mathrm{m}$; nuclei blue with DAPI). $\boldsymbol{b}, V_{\mathrm{m}}$ during four cycles of scratching (of 7 total) elicited by tactile activation, onset indicated $(\Delta)$ ). $\boldsymbol{c}$, Three sample trials with different current (top) and their spike rates (bottom, peaks selected). $\boldsymbol{d}$, Peak spike rates for all trials $(n=43)$ with different current injections for each cycle (RI curves). Fitted lines overlay in cycle 4. $\boldsymbol{e}$, Slopes of lines (mean and span indicated). $\boldsymbol{f}$, Histogram of normalized gain span ( $\max -\mathrm{min} / \mathrm{mean}$ ) across motoneurons. $\boldsymbol{g}$, Coefficient of variation of gain across motoneurons. Sample cell location indicated ( $\star$ ).

$\geq 2$ orders of magnitude of data are required to make a clear distinction between the two. The curvature dependence on synaptic fluctuations was assessed by the SD of the distribution of $V_{\mathrm{m}}$ traces before the spike in the diffusion regime, i.e., where there was no link to the $V_{\mathrm{m}}$ and the spike occurrence. This distribution was chosen $15 \mathrm{~ms}$ before the spike (see Fig. $6 A$ ). The analysis and fits were performed in Matlab with generic fitting functions.

\section{Results}

\section{Subsecond gain modulation of motoneurons}

To investigate whether the input/output (IO) gain of motoneurons is being modulated, we recorded intracellularly from motoneurons. Small injected constant current was used as input to imitate the summation of many synaptic currents and the spike rate was defined as the output. Motoneurons were often identified via histological colocalization of the recorded cell (stained red with biocytin) and ChAT-positive cells (green) in the ventral horn (Fig. 2a). During the scratching motor behavior, these cells received rhythmic synaptic input from a premotor network (Fig. $2 b)$, while the injected current was constant $\left(I_{i n j}=0 \mathrm{nA}\right.$ in this case). The scratching motor program was initiated by a tactile stimulus delivered on the skin (onset is indicated by a triangle). We initiated the scratching motor program over multiple trials with different constant current injections and estimated the peak spike rate for each cycle (Fig. $2 c$ ). The peaks were used since they were well defined in time and therefore gave the smallest variability across trials (Fig. $2 c$, cycle 2 ). The peak spike rate could then be plotted for each cycle and current injection (Fig. $2 d$ ). This formed the basis for estimating the RI function of each cycle, which permitted verification of a systematic modulation of gain from cycle to cycle. Though the slope of the RI function is likely not constant for all input, we suggest that the injected current represented only a small perturbation such that a linear response is a valid approx- 


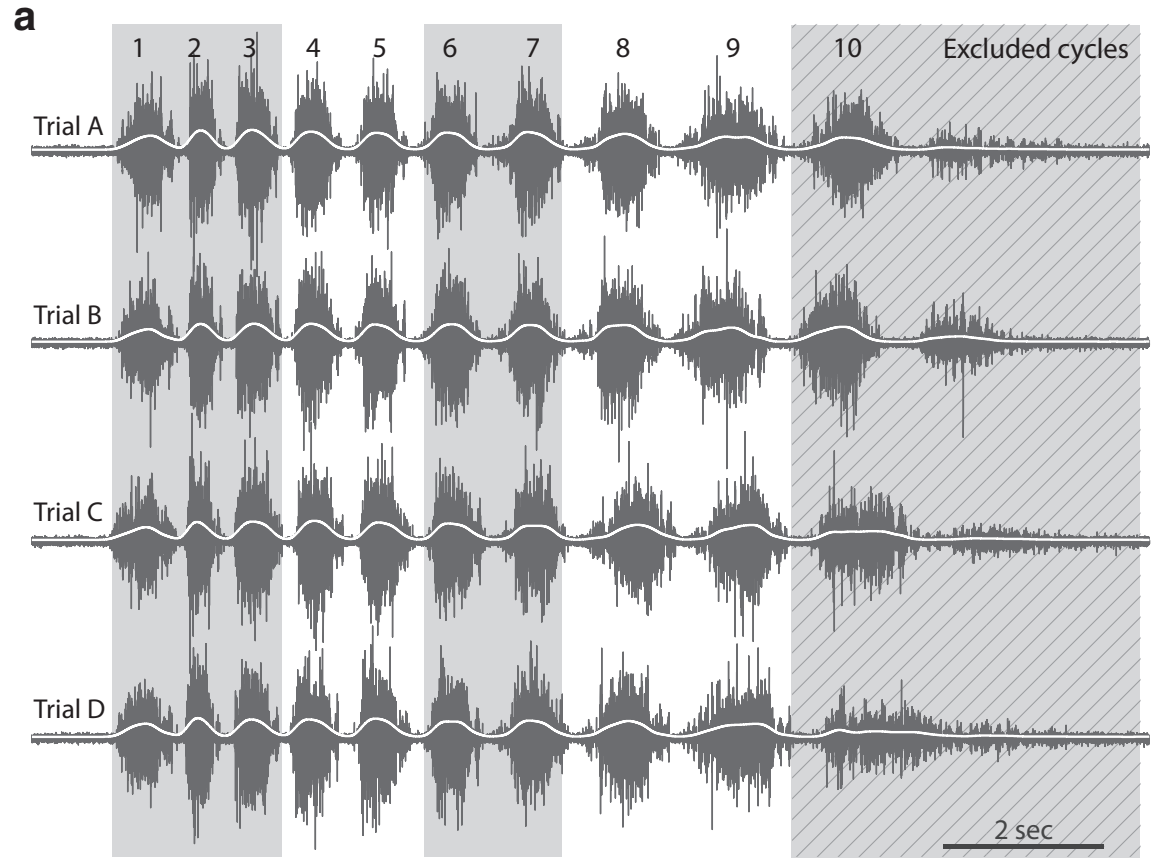

b

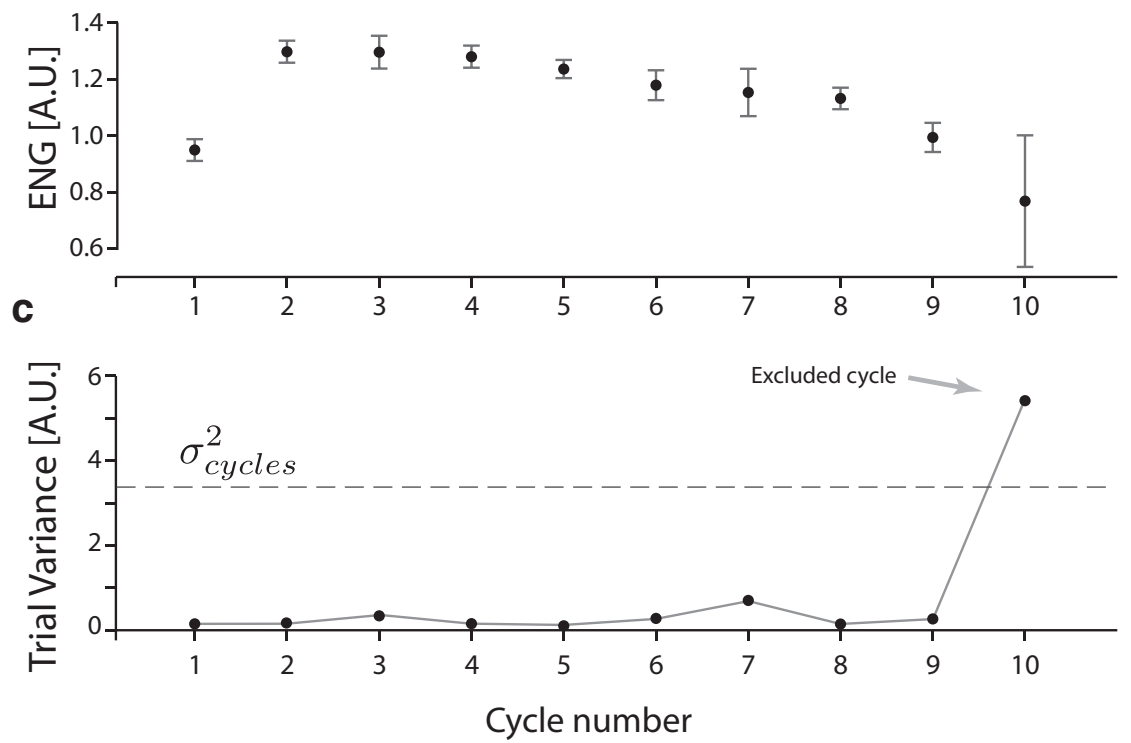

Figure 3. Motor pattern activity induced by repeated tactile stimulation is highly reproducible across trials. $\boldsymbol{a}$, Hip flexor nerve activity of four consecutive trials of scratching shows modulation of ENG, i.e., a force correlate, across cycles, but marginal trial variability. Peak of filtered overlay (white) is metric for trial comparison. $\boldsymbol{b}$, The modulation of force across cycles is measured in terms of trial-averaged ENG with small error bars $( \pm S D)$ compared with the cycle-to-cycle modulation. $c$, The variance of ENG activity across trials is small compared with the cycle-to-cycle variance (broken line), except for cycle 10, which has a larger trial-to-trial variance and is therefore excluded from the analysis ( $\boldsymbol{a}$, striped region).

imation. We therefore quantified the gain as the slope of the linear fit in the RI function (shown in gray). We found that the motoneuron gain was different from cycle to cycle [(Fig. 2d,e, compare broken lines $(d)$, bars $(e)]$.

To compare gain modulation across motoneurons, which may have different biophysical properties, we quantified the extent of gain modulation using the metric gain span, which we defined as the maximum minus minimum gain normalized by the mean. The neuron had relatively large span of $41 \%$ (Fig. 2e). We repeated the experiment and analysis for a population of motoneurons $(n=25)$ and found that the gain modulation of the sample cell was in the lower end. The gain span across the population was from 40 to $200 \%$ [Fig. $2 f$, sample cell location indicated $(\star)]$. As a more conservative alternative to gain span, we used the coefficient of variation $(\mathrm{CV})$, i.e., the $\mathrm{SD}$ of gain normalized by its mean. The $\mathrm{CV}$ across the population had a range from 20 to $100 \%$ (Fig. $2 g$ ). These results indicate that neuronal gain was modulated from cycle to cycle in all spinal motoneurons. Since the cycle period was often $<1 \mathrm{~s}$ the process responsible for the gain modulation must have dynamics on a timescale of $<1 \mathrm{~s}$. For this reason, we characterize the modulation as subsecond gain modulation.

\section{Gain modulation optimizes motor control}

What would be the purpose of having such a large range of motoneuron gain? Since neuronal gain is the amplification of the spike-rate output to a given synaptic input, the same input variability will be amplified to a larger spike-rate variability for high-gain conditions compared with low-gain conditions. The spike-rate variability of motoneurons is converted into variability in muscle force $(\Delta F$; Dideriksen et al., 2012), so higher gain in the motoneuron is associated with higher variability in force. When the motor system is optimized to keep the relative variability constant $(\Delta F / F \approx$ constant $)$, we would expect less variability in the spike rate when the total force is low compared with when the total force is high. Thus, the gain of motoneurons, which represents the amplification of fluctuations from the premotor system to fluctuations in force, should correlate with the total force (Fig. $1 c)$, i.e.,

$$
\text { gain } \propto \text { force }
$$

Our prediction is therefore that a motoneuron participating in controlling a stronger force will have a steeper gain function than when participating in controlling a weaker force (Fig. 1c). The force was quantified as the rectified and filtered motor nerve ENG, since this signal represented the motoneuron population activity. The ENG signal likely contains the activity of different kinds of motor units, including the fast-twitch fatigable, fast-twitch fatigue-resistant, and slow motor units, which all have different muscular properties (Burke, 1981). A distinction between the classes is not necessary in the present study since the crucial assumption applies to all motor units. The assumption is a monotonic relationship between the ENG activity and the output force, i.e., the stronger the nerve activity the larger the force. A monotonic relationship between rectified and integrated ENG/electromyogram and force is well established (Burke, 1981; Henneman 

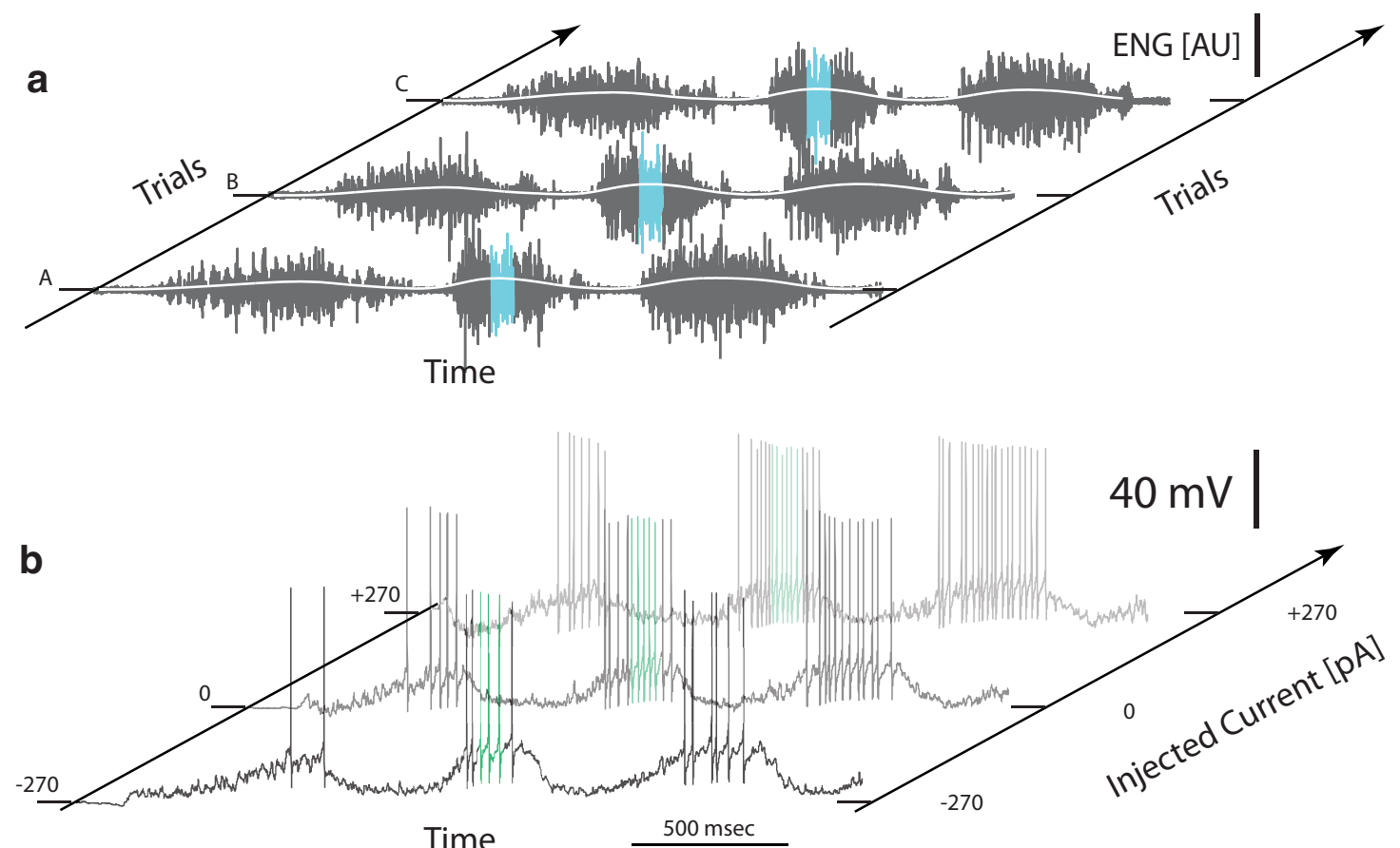

C

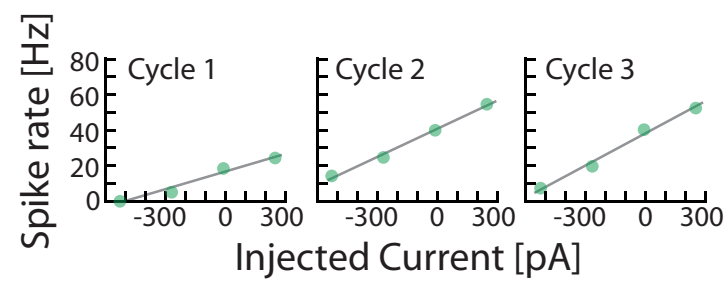

d

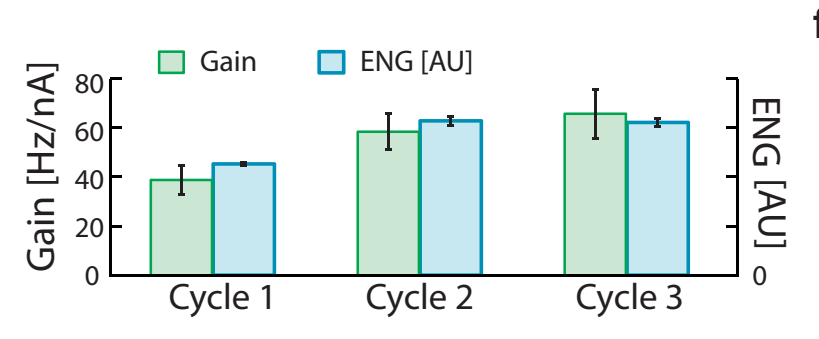

e

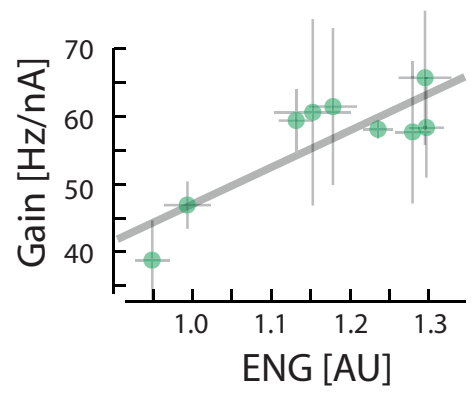

f

Correlation Coefficients

Figure 4. Motoneuron gain correlates with motor nerve activity. $\boldsymbol{a}$, ENG of the three first cycles (Fig. 3) shown for multiple trials. Peak of filtered overlay (white) is metric for trial comparison and force correlate, i.e., ENG (highlighted blue). $\boldsymbol{b}$, Concurrent $V_{\mathrm{m}}$ traces with different current injections to probe spike-rate sensitivity at peak nerve activity (sample cycle highlighted in green). $\boldsymbol{c}$, RI curves of each cycle. $\boldsymbol{d}$, Gain (green) and ENG (blue) for each cycle (average peak nerve activity, $95 \%$ confidence limits). The error bars for the ENG are the SD of the three trials shown in $\boldsymbol{a}$. The error bars of gain are the SD for the linear fit in c. $\boldsymbol{e}$, Gain and peaknerve activity for the sample data (the first 9 cycles) are correlated $(p<0.001$ ). $\boldsymbol{f}$, Histogram of correlation coefficients for population (sample motoneuron indicated by arrow).

and Mendell, 1981; Fuglevand et al., 1993; Enoka and Fuglevand, 2001). The relationship is even linear for muscles with homogeneous fiber-type composition (Guimaraes et al., 1994).

We tested the hypothesis of a gain $\propto$ force relationship by relating the motoneuron RI gain with the ENG as a surrogate for force. The ENG was regulated from cycle to cycle intrinsically by the network during the complex pattern of motor behavior (Fig. $3 a$ ). Though the ENG changed from cycle to cycle within a trial, the pattern was remarkably similar across trials (Fig. $3 a$, compare cycles across trials). The peak value of the nerve activity in each cycle was averaged across trials and their low SD revealed a highly reproducible modulation of the ENG across episodes (Fig. $3 b$ ).
We used the low variance across trials as a measure of how reproducible the pattern was in comparison with the variance of modulation within a trial. If the trial-to-trial variance $\left(\sigma_{j}^{2}\right)$ was larger than the cycle-to-cycle variance $\left(\sigma_{\text {cycles }}^{2}\right)$, the cycle was excluded from the analysis (Fig. $3 c$ ). In those cases, it was always the last cycle(s) (Fig. $3 a$, striped area). The $V_{\mathrm{m}}$ of a corresponding motoneuron was simultaneously recorded for each trial with different input current (Fig. $4 a, b$, cycle 2 highlighted in green) to estimate the RI function for each cycle (Fig. 4c), as described previously (Fig. $2 b, c$ ). The ENG in each cycle was compared (in arbitrary units) with the corresponding gain for the first three cycles, which indicated a covariation (Fig. $4 d$ ). We plotted the 

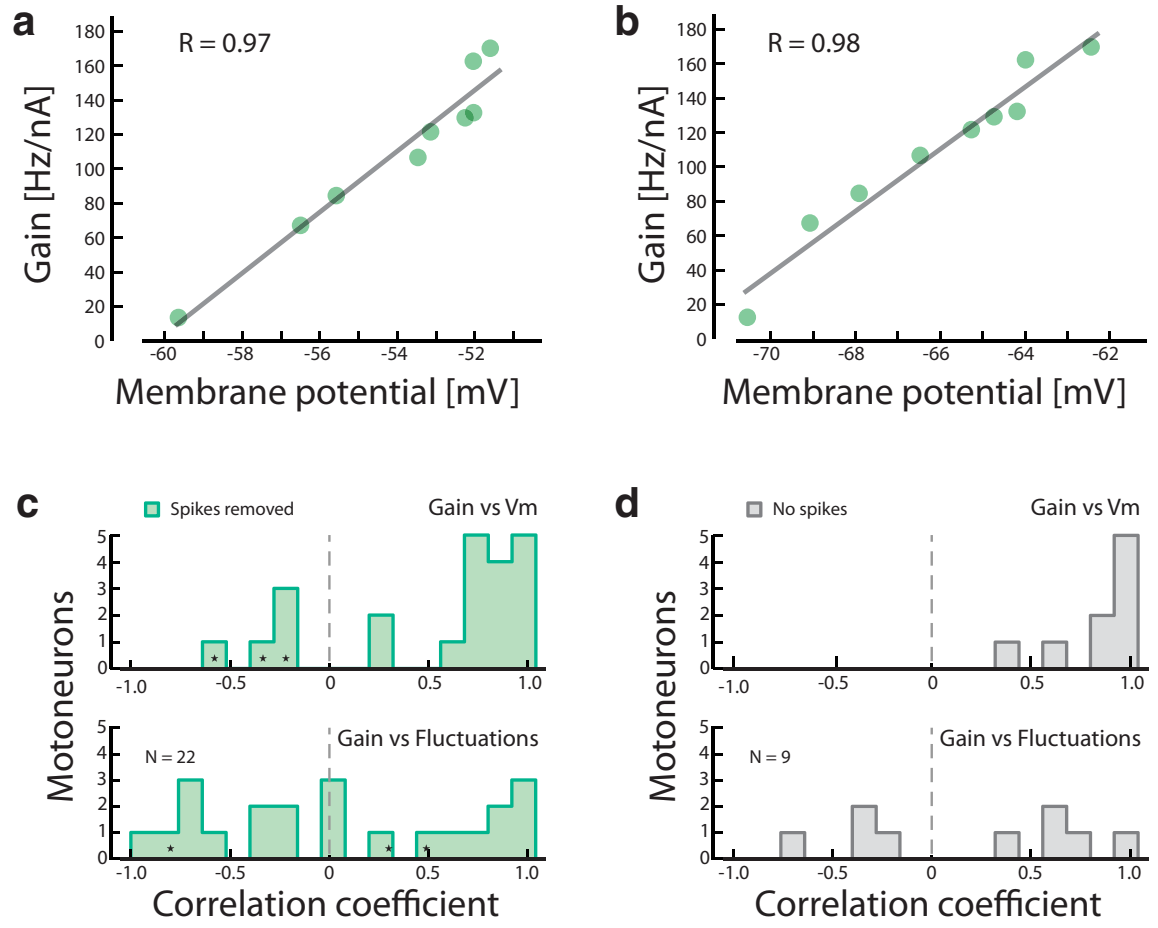

Figure 5. Gain and $V_{\mathrm{m}}$ are correlated. $\boldsymbol{a}, \boldsymbol{b}$, Gain is correlated with mean $V_{\mathrm{m}}$ averaged over a $200 \mathrm{~ms}$ window around the peak of corresponding cycles where the spikes were removed $(\boldsymbol{a})$ and where $V_{\mathrm{m}}$ was hyperpolarized $\left(I_{\text {inj }}=-500 \mathrm{pA}\right)$ to avoid spikes $(\boldsymbol{b})$. $\boldsymbol{c}$, $\boldsymbol{d}$, Top, Correlation coefficients between gain and $V_{\mathrm{m}}$ with spikes removed $(\boldsymbol{c})$ and hyperpolarized (d). Bottom, Correlation between gain and SD of a spike removed $(\boldsymbol{c})$ and hyperpolarized $(\boldsymbol{d})$. Datasets having uncorrelated ENG and gain indicated ( $\star$ ).

gain for the first nine cycles against the corresponding force $(\mathrm{ENG})$ and found a significant correlation between the two (Fig. $4 e$ ); hence, gain is indeed proportional to force, as hypothesized. A significant majority ( $n=22$ of 25$)$ of the population also had positive correlation coefficients (Fig. $4 f$ ). Hence, the neuronal gain was modulated in a manner consistent with a minimization of the effects of variance by keeping the relative uncertainty constant (Hatze, 1979; Senn et al., 1997; Jones et al., 2002).

\section{Relationships among gain, spike rate, and $V_{\mathrm{m}}$}

Though integrative properties of motoneurons have been investigated extensively (Perrier and Hounsgaard, 2000; Rekling et al., 2000; Hultborn et al., 2003; Heckman et al., 2009), it is unclear how the gain observed in the present study was being modulated, especially since it was too swift to involve neuromodulators. Nevertheless, we noticed that the mean $V_{\mathrm{m}}$ was different from cycle to cycle just as the gain was, and these could potentially correlate. To investigate such a correlation, it was necessary to estimate the mean $V_{\mathrm{m}}$ in the absence of spikes, since spikes biased the mean to larger values. To circumvent this bias, we estimated the mean $V_{\mathrm{m}}$ in two ways. First, we removed the spikes from those trials with few spikes and time-averaged the $V_{\mathrm{m}}$ over a small window on the peak of each cycle. Second, we cleared the spikes altogether by injecting a hyperpolarizing current and then time-averaged $V_{\mathrm{m}}$ over a window on the peaks. The mean $V_{\mathrm{m}}$ in the latter method should have more negative values, but this will not affect the correlation measure. Results of both estimates showed a positive correlation with the gain of the corresponding cycle (Fig. 5a,b). We also tested this for the population of motoneurons and the majority ( $n=17$ of 22) had a similar positive correlation (Fig. $5 c$, top). The negative correlation for a subset of cells ( $n=3$ of 22) was attributable to their zero or negative correlation between gain and ENG signal (indicated with stars). We were unable to explain the negative correlation in the remaining two cells. The second way of estimating the mean $V_{\mathrm{m}}$ had smaller sample size, but similar trend (Fig. 5d).

One mechanism that has been frequently suggested as a possible means for modulating gain on short timescales involves synaptic "background fluctuation" (Ho and Destexhe, 2000; Chance et al., 2002). If a similar mechanism were responsible for modulating the gain of motoneurons, we should also see a relationship between gain and the fluctuations in $V_{\mathrm{m}}$. An increasing level of fluctuations will lead to smaller gain, so we would expect a negative correlation between gain and fluctuations. We tested the hypothesis and it was not compatible with our data, since the correlation coefficient had no consistent trend (Fig. $5 c, d$, bottom). This is perhaps not unexpected because the fluctuations would have to decrease as the force level and mean synaptic input increase, making synaptic fluctuations to control gain difficult to implement in the motor system. This is problematic to reconcile with the previous finding of signal-dependent noise in the motor system (Harris and Wolpert, 1998; Jones et al., 2002; Faisal et al., 2008; Watanabe et al., 2013) and the general increase in $V_{\mathrm{m}}$ fluctuation for increasing synaptic input (Kolind et al., 2012). Last, the synaptic fluctuations are expressed as the variance in $V_{\mathrm{m}}$, which is the second moment. Second moments are notoriously difficult to determine, and fluctuations would therefore be an inaccurate parameter to communicate in motor networks.

Instead, we suggest the increase in IO gain could be explained by an expansive nonlinearity (Hansel and van Vreeswijk, 2002; Miller and Troyer, 2002) between spike intensity and mean $V_{\mathrm{m}}$ (Fig. 6a,b). An expansive nonlinearity is a class of nonlinear functions like power laws and exponentials. This type of function has an upward increase in curvature such that an interval on the $x$-axis is expanded on the $y$-axis. Synaptic fluctuations can create this expansive nonlinearity between $V_{\mathrm{m}}$ and spike rate by broadening the threshold into the subthreshold domain (Miller and Troyer, 2002; Mitchell and Silver, 2003). The larger the fluctuation in $V_{\mathrm{m}}$, the weaker the nonlinearity consistent with the hypothesis that increased "background fluctuations" cause lower gain (Hô and Destexhe, 2000; Chance et al., 2002). We observed this effect as a mild negative correlation between fluctuations in $V_{\mathrm{m}}$ and curvature of the expansive nonlinearity (Fig. $6 c$ ). Theoretical studies have shown that the expansive nonlinearity between spike intensity and mean $V_{\mathrm{m}}$ makes gain modulation possible by changing the mean synaptic input without requiring a change in fluctuations (Hansel and van Vreeswijk, 2002; Miller and Troyer, 2002; Silver, 2010). If the gain modulation observed in the present study was conducted by adjusting $V_{\mathrm{m}}$, we should see a correlation between the two, which we did (Fig. 5).

In this part of the analysis, we used the metric spike intensity (Fig. 6b) as a better alternative to spike rate, since the relationship between spike rate and $V_{\mathrm{m}}$ is ill defined when $V_{\mathrm{m}}$ is repeatedly 
a

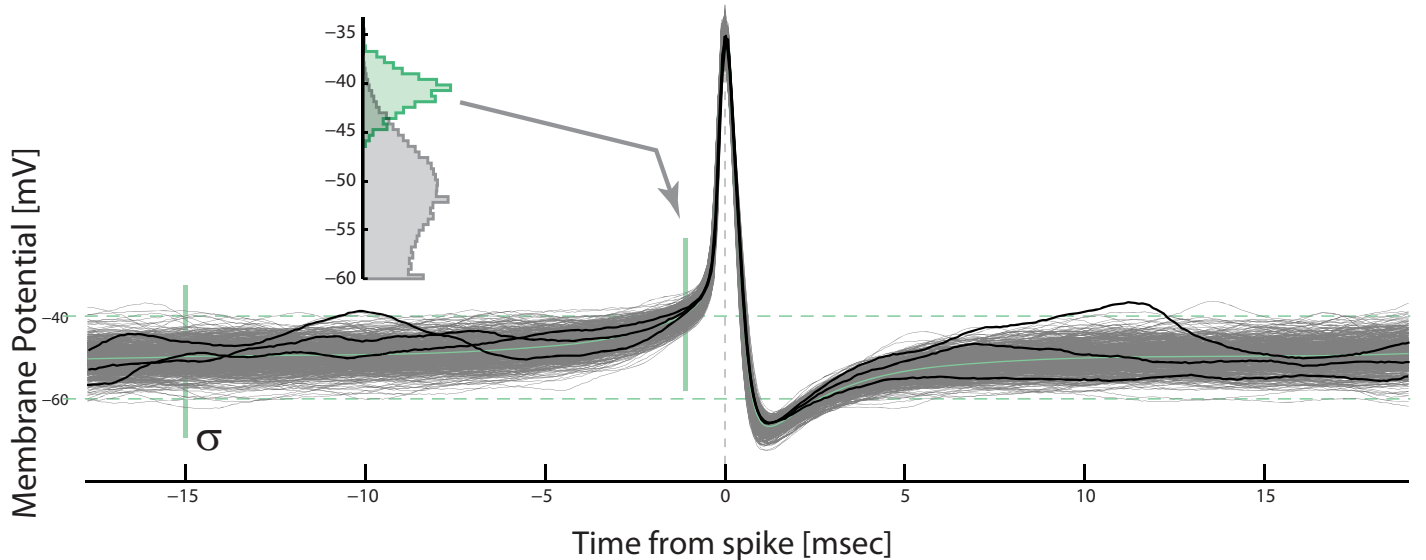

b

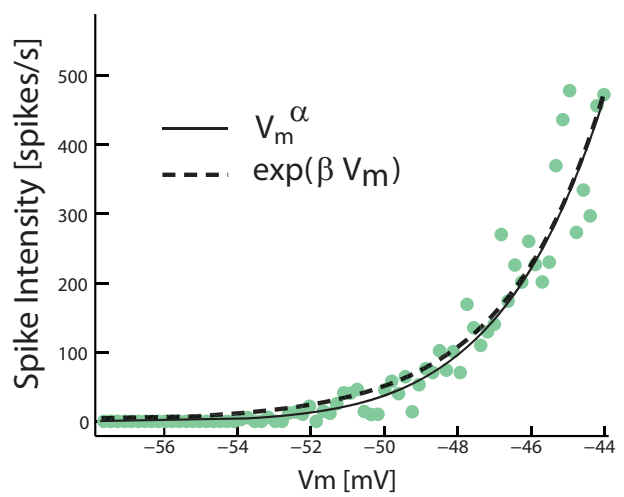

C

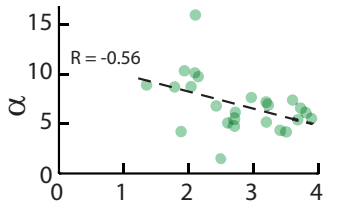

Standard Deviation of $\mathrm{Vm}[\mathrm{mV}]$

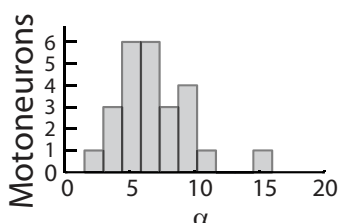

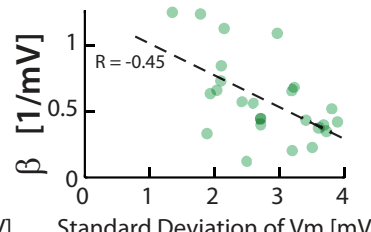

Standard Deviation of $\mathrm{Vm}[\mathrm{mV}]$

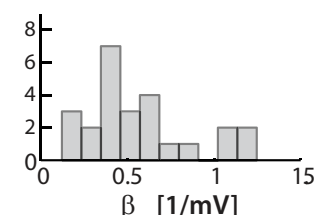

Figure 6. Expansive nonlinearity between $V_{m}$ and spike intensity. $\boldsymbol{a}$, The spike-intensity function is empirically estimated as the $V_{m}$ distribution 1.5 ms before spike (green inset histogram at vertical green bar) in the spike-triggered spike overlay $(n=519)$ normalized by the total time spent at each value of $V_{m}$ (gray histogram). Three sample traces shown in black; mean shown in green. The left vertical bar represents the location of the sampled $\mathrm{SD}(\sigma)$ used in $\boldsymbol{c} . \boldsymbol{b}$, The corresponding spike intensity versus $V_{\mathrm{m}}$. An exponential and a power law are fitted to capture the curvature of the expansive nonlinearity. $\boldsymbol{c}$, The curvatures measured as the $\alpha$ in the power law fit ( $V_{m}^{\alpha}$ left) or as $\beta$ in the exponential fit ( $\exp \left(\beta V_{m}\right)$, right) plotted for different motoneurons, show decrease with size of fluctuation (SD of $V_{\mathrm{m}}$ in the diffusion regime, at $15 \mathrm{~ms}$ before the spike; see $\sigma$ in $a ; r=-0.56, p \ll 0.01$ for $\alpha ; r=-0.45, p=0.03$ for $\beta$. Bottom, Distribution of the curvature measures $\alpha$ (left) and $\beta$ (right).

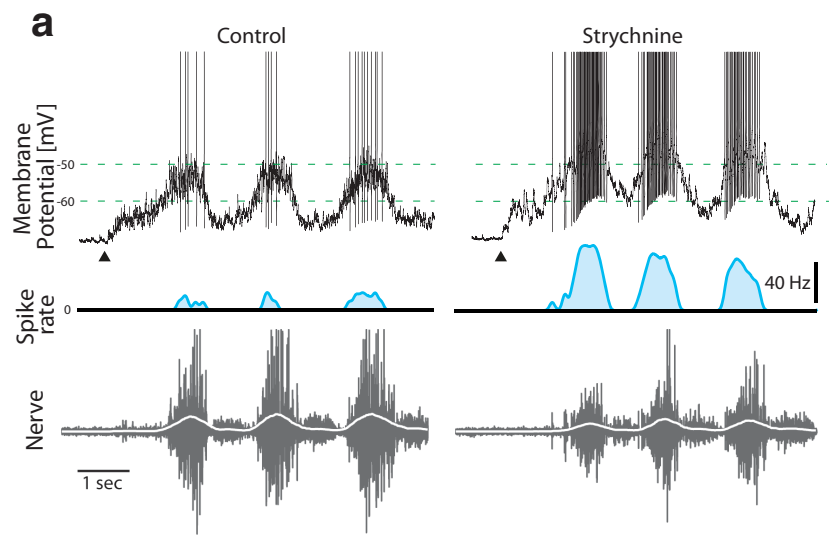

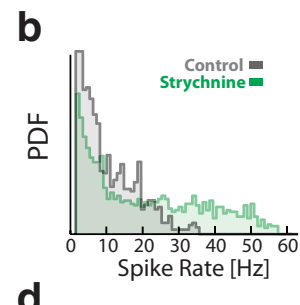

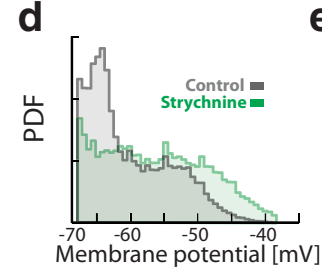

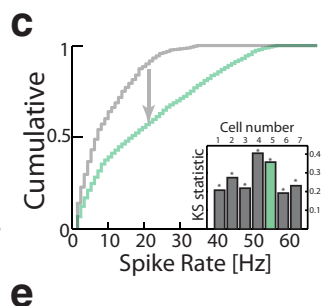

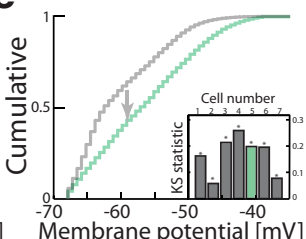

Figure 7. Inhibition affects spiking and $V_{\mathrm{m}}$ during on cycle. $\boldsymbol{a}$, Top, $V_{\mathrm{m}}$ of sample motoneuron before and after strychnine during motor patterns (onset indicated by triangles). Spikes clipped at $-20 \mathrm{mV}$. Middle, Spike rate. Bottom, Concurrent ENG. $\boldsymbol{b}$, The spike rate increases following strychnine application as seen by a rightward shift in the PDF (control in gray and after strychnine in green). c, The increase is quantified by the downward shift in the cumulative distribution (arrow), i.e., the Kolmogorov-Smirnov (KS) test statistic. Inset, The KS statistic for all cells, sample cell in green. All have significant increase $(p<0.05)$. $\boldsymbol{d}, \boldsymbol{e}$, The distribution of subthreshold $V_{\mathrm{m}}$ is also depolarized more following strychnine application $(\boldsymbol{d})$, which is similarly quantified by the shift in the cumulative distribution (e). All cells have significant change (inset bar graph, green indicates the sample cell KS statistic, $p<0.05$ ).

reset after spikes. The spike intensity is the empiric probability of obtaining a spike in a small time window for a given $V_{\mathrm{m}}$, and this probability is an expression of the neuronal sensitivity (Jahn et al., 2011). It is estimated as the distribution of $V_{\mathrm{m}}$ before the spike in the triggered histogram (Fig. $6 a$, green histogram) normalized by the total time spent at each $V_{\mathrm{m}}$ (gray histogram). This is similar to the spike rate when spiking can be approximated as a renewal process. The spike intensity had a magnified sensitivity to excit- 

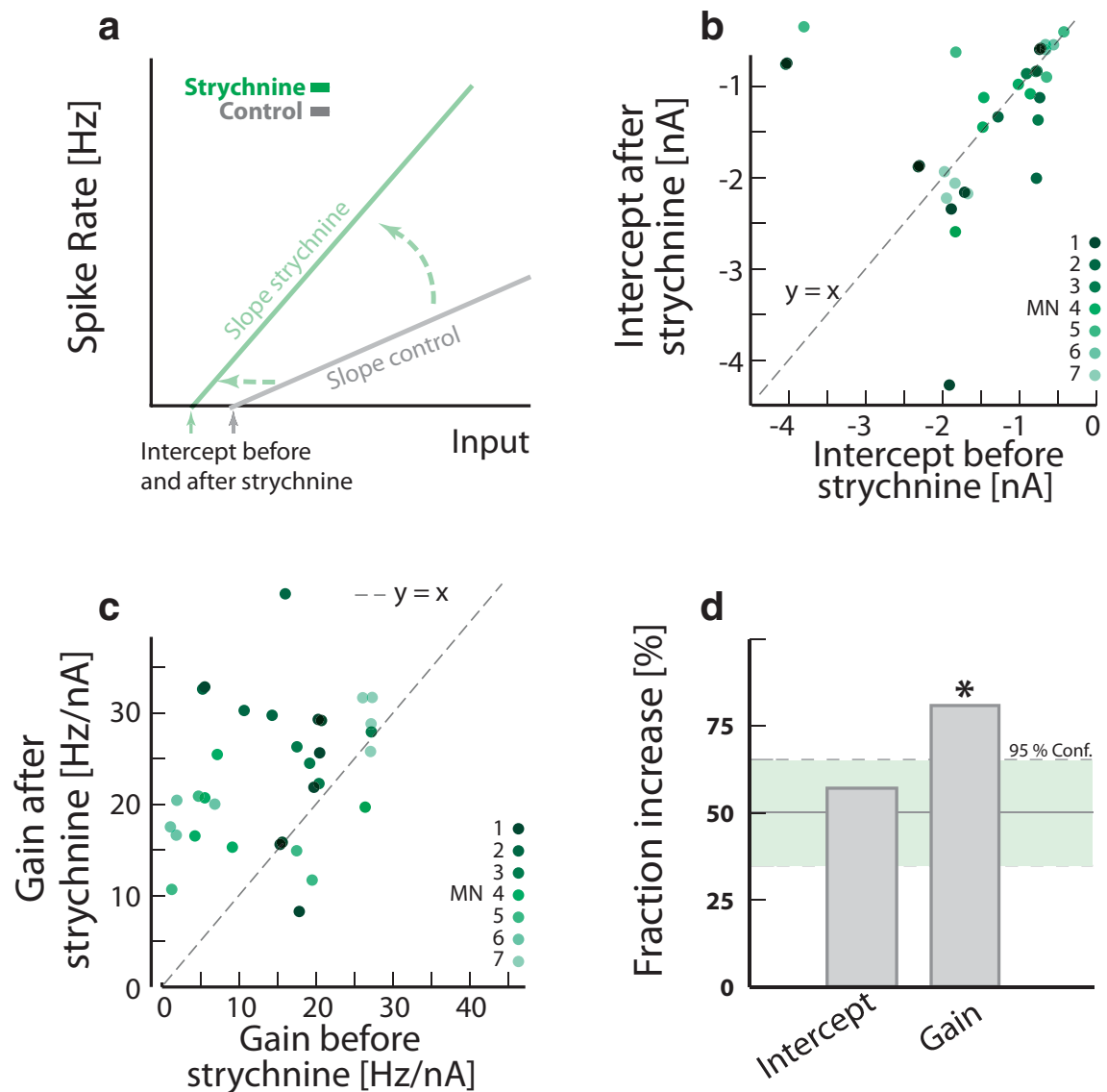

Figure 8. Inhibition has a divisive rather than subtractive effect on the RI gain. $\boldsymbol{a}$, Blocking inhibition can have two effects: (1) a change in the slope, i.e., a divisive/multiplicative change of gain, or (2) a change abscissa intercept, i.e., subtractive/additive change (arrows). $\boldsymbol{b}$, The intercepts for all cycles of all cells (color code indicated) plotted before (abscissa) versus after strychnine (ordinate). Broken line is the unity line (57\% data points above). c, Gain of the RI curves for control versus blocked inhibition ( $81 \%$ above unity line). $\boldsymbol{d}$, There is no significant change in the intercept following strychnine application as quantified by the fraction above the unity line (in $\boldsymbol{b}$ ). There is, however, an increase in the gain, since there is a significant fraction of points above the unity line (in c) using binomial statistics.
(PDF) of the spike rates (Fig. $7 b$ ) and a downward shift in the cumulative distribution (Fig. 7c). The shift was measured across the population of motoneurons as the largest vertical difference between the curves, i.e., the Kolmogorov-Smirnov two-sample test statistic. The spike-rate increase was significant in all cells (inset). Similarly, when the glycinergic inhibition was reduced, the PDFs shifted toward higher values (Fig. $7 d, e$ ). Together, these data suggest that inhibition adjusts the spike rate and $V_{\mathrm{m}}$ and therefore could be involved in modulating the gain of motoneurons (Hansel and van Vreeswijk, 2002; Murphy and Miller, 2003).

The flow of strychnine solution was carefully controlled such that it would affect only the recorded motoneuron and few premotor neurons in the surface. Of the few premotor interneurons, we expect only few, if any, to project to the recorded motoneuron. Since most synaptic input has widely distributed origins in rostral segments (Berkowitz and Stein, 1994; Guzulaitis et al., 2014), indirect side effects, such as disinhibition of excitatory premotor neurons and other motoneurons, were therefore negligible. This was also evident from the nerve activity, since it did not increase (Fig. $7 a$ ). In this sample data there was even a decrease in nerve activity, which was attributable to general trial variability or desensitization of the network. In the majority of experiments, there was no notable difference in ENG (data not shown).

\section{Divisive modulation by inhibition}

atory synaptic potentials with increasing mean $V_{\mathrm{m}}$ (Fig. 6b; Hansel and van Vreeswijk, 2002; Miller and Troyer, 2002). Because of this magnification in sensitivity to $V_{\mathrm{m}}$, and the correlation between gain and $V_{\mathrm{m}}$ (Fig. 5), we suggest that mean $V_{\mathrm{m}}$ is the primary determinant of the gain modulation observed in the present study.

\section{Concurrent inhibition reduces $V_{\mathrm{m}}$ and spike rate}

What are the important factors determining the mean $V_{\mathrm{m}}$ ? The mean $V_{\mathrm{m}}$ is set not only by excitatory synaptic input, but also by the inhibition. Prior experiments have shown that motoneurons often receive both excitation as well as inhibition simultaneously during motor behaviors (Parkis et al., 1999; Saywell and Feldman, 2004; Berg et al., 2007; Johnson et al., 2012; Petersen et al., 2014). Our next objective was therefore to manipulate the synaptic input to verify a causal link between $V_{\mathrm{m}}$ and gain. Since excitation is necessary for the spiking output, manipulating inhibition was more relevant. We chose to investigate the glycinergic inhibition, since glycine is the primary inhibitory neurotransmitter in the spinal cord (Rekling et al., 2000). The competitive antagonist strychnine was applied locally to the cut surface at the caudal end of the spinal cord. We then tested the effects of the strychnine application and found that the spike rate had a sizable increase (Fig. $7 a$, blue trace). This increase was quantified by a rightward shift in the probability density function
In the previous section we used strychnine to manipulate the synaptic input and indirectly control $V_{\mathrm{m}}$, but a potential causal link between $V_{\mathrm{m}}$ and the neuronal gain was not addressed. To tease apart the effects of inhibition and $V_{\mathrm{m}}$ on the motoneuron gain, we classified the modulation as either subtractive (rightward shift) or divisive, i.e., decreasing the slope (Murphy and Miller, 2003; Silver, 2010). The reduction in inhibition via strychnine would have opposite effects, i.e., additive and multiplicative (Fig. 8a). We tested the additive/subtractive effects by plotting the abscissa intercept for all cycles of each motoneuron before versus after the application of strychnine (Fig. 8b). If there was a consistent decrease, there should be more points below the unity line than above (broken line). We tested this and found an approximately even distribution above compared with below. This suggests that there was no clear increase or decrease of the set point of the RI curve associated with reduction in inhibition. However, when the same analysis was repeated for gain, there was significantly more data points above the unit line (Fig. $8 c$ ). In summary, the fraction of points above unity line had no significant difference regarding the additive/subtractive modulation, whereas there was a significant increase in the slope (Fig. $8 d$ ), which suggests a divisive rather than subtractive role of inhibition.

Next, we wanted to investigate the IO gain using a different input than injected current. Since the ENG activity represents the 
common activity of the motoneuron pool (Senn et al., 1997), we used this activation as a proxy for the common synaptic excitation to motoneurons. This measure is also more robust against variability in network activity, e.g., desensitization of the response to the tactile activation. We therefore performed an alternative analysis, now keeping the injected current constant and measuring the spike rate as a function of ENG activity (RN function). The RN function of a sample motoneuron is shown before and after strychnine application (Fig. 9a). Again, we tested the intercept before and after strychnine by plotting them against each other for all cycles of all motoneurons to assess the potential subtractive effect of inhibition (Fig. 9b). Similarly, we tested whether the effect of inhibition was divisive versus multiplicative (Fig. 9c). We counted the fraction of points above versus below the unity line and found no significant change in intercept. Nevertheless, there was a significant increase in gain (Fig. $9 d$ ), suggesting again that inhibition has primarily a divisive effect. Together these results demonstrate the following: (1) that there is a causal link between gain modulation and $V_{\mathrm{m}}$ and (2) that glycinergic inhibition has a role in adjusting the integrative properties of motoneurons.

As a control to verify that the seal of the nerve recording did not change over time, the background ENG level was measured for all trials in all motoneurons and plotted before and after application of strychnine. There was no significant different between number of points above versus below, suggesting that the background level did not change (Fig. 9d).

\section{Discussion}

In this study, we have addressed the presence, purpose, and mechanism of gain modulation in spinal motoneurons. We found first, that the gain can be modulated from cycle to cycle often on a subsecond timescale. Second, we found that this modulation is correlated with the magnitude of force in accordance with optimal control theory (Hatze, 1979; Harris and Wolpert, 1998; Todorov, 2004; Faisal et al., 2008) where the relative variability $(\Delta F / F)$ is constant throughout the dynamic range. Third, the gain modulation is likely accomplished via an expansive nonlinearity by adjusting the mean $V_{\mathrm{m}}$, where inhibition has a divisive influence.

\section{Gain control of neurons in the nervous system}

Active gain modulation of motoneurons has been investigated, especially in connection with slow neuromodulatory effects (Rekling et al., 2000; Miles et al., 2007; Heckman et al., 2009; Wei et al., 2014), but whether gain modulation participates in optimal motor control is still unresolved (Johnson and Heckman, 2014).

Neuronal gain modulation has been observed in other systems (Mitchell and Silver, 2003; Silver, 2010; Wilson et al., 2012; Polack et al., 2013), and the link to physiology has often been suggested in connection with processing of sensory input. For is assessed via binomial statistics.
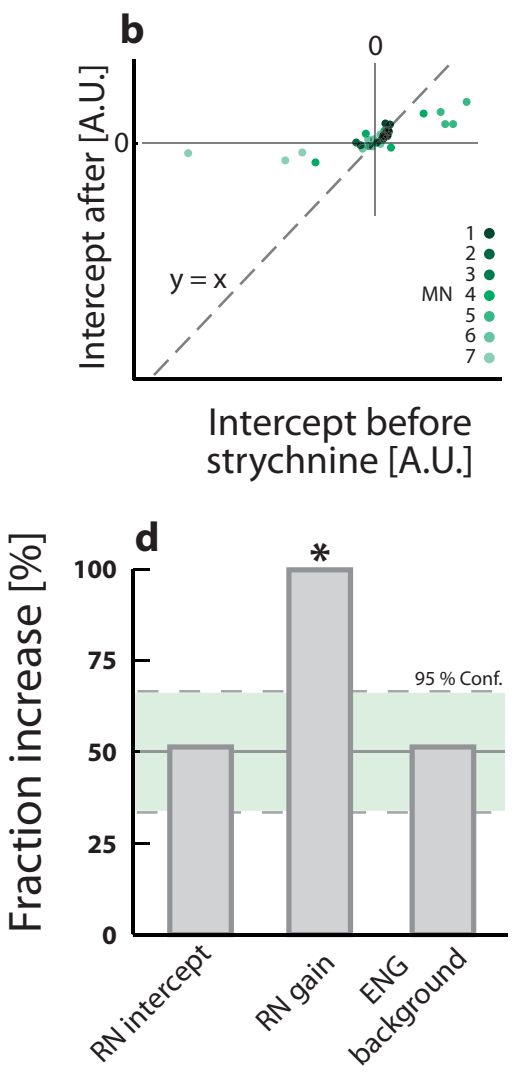

Figure 9. Inhibition also has a divisive effect on the RN function. $\boldsymbol{a}$, The 10 function before (gray) and after (green) strychnine, (ifferent motoneurons, as indicated. c, Gain of RN curves before versus after strychnine application, with 100\% bove identity line (broken line). $\boldsymbol{d}$, Fraction above unity line in intercept, slope, and background ENG, with the $95 \%$ significance,

instance, normalization of tuning curves in primary visual cortex is likely to be beneficial in widening the dynamic range of visual sensation (Carandini and Heeger, 2012). Also, rescaling of sensitivity to changing contrasts in sound is likely beneficial in auditory processing (Rabinowitz et al., 2011). For motoneurons, the receiver of the axon projections is well defined and the purpose of each action potential is unambiguous. This offers a unique opportunity to establish a clear connection between modulation of neuronal gain and physiology. In the present study we suggest that there is such a link since the observed gain modulation is performed in a manner that increases precision of force, similarly to the way orderly recruitment of motor units optimizes control of force (Stein et al., 2005).

Gain modulation is traditionally considered to be performed by a separate system, e.g., either a "background synaptic activity" (Hô and Destexhe, 2000; Chance et al., 2002) or a neuromodulatory input (Rekling et al., 2000), with the sole purpose of modulating sensitivity to a driving input (Silver, 2010). Our findings suggest that the mean $V_{\mathrm{m}}$ itself could work as gain modulator by increasing sensitivity of synaptic potentials via the expansive nonlinearity. This is akin to the correlation observed between membrane depolarization during different cortical states and the gain of layer 2/3 neurons (Polack et al., 2013), though metabotropic modulation also has an influence. In this way, the observed modulation is not a gain modulation in the traditional sense, but rather a dynamical adjustment by both the intensity and ratio of synaptic excitation and inhibition from the premotor network 
(Murphy and Miller, 2003). This type of input could be generated by a simple recurrent architecture where feedforward and feedback excitation and inhibition is widespread. The potential benefit of modulating gain in this simple way could be to abolish the need for central orchestration and instead let the local network adaptively adjust sensitivity.

Other mechanisms of gain modulation, such as neuromodulatory input from the brainstem, can activate voltage-sensitive channels causing persistent inward currents and plateau potentials in motoneurons (Hounsgaard and Kiehn, 1989; Perrier and Hounsgaard, 2000; Heckman et al., 2009). This will likely amplify the expansive nonlinearity in spike output and make it even more sensitive to the $V_{\mathrm{m}}$. The extent of this effect is dependent on the mixture of excitation and inhibition (Kolind et al., 2012; Powers et al., 2012), and the synaptic conductance can suppress the otherwise prominent intrinsic response properties (Alaburda et al., 2005). Another suggested mechanism to be in play in the motor system relates to the hypothesis of "recruitment gain" of the motoneuron pool, where the range of thresholds for the different motoneurons in the pool can be compressed or expanded, depending on the motor task (Kernell and Hultborn, 1990).

\section{Inhibition in the spinal cord}

The observation that inhibition has a substantial influence on motoneurons during muscle contraction has been documented previously in control of turtle hindlimbs (Berg et al., 2007) and rat respiratory system (Parkis et al., 1999; Saywell and Feldman, 2004; de Almeida and Kirkwood, 2010), and during voluntary precision wrist/grip movements in monkeys (Takei and Seki, 2013; Wu and Perlmutter, 2013). Where does the inhibition come from? One possibility is recurrent inhibition, which is omnipresent in the CNS (Windhorst, 1996). The most evident example is the reflex circuitry involving the Renshaw interneuron, which is an inhibitory interneuron that is activated by a motoneuron axon collateral. These interneurons provide recurrent inhibition directly onto the motoneurons and, it has been suggested, are involved in the divisive modulation of motoneuron gain (Hultborn et al., 1979). It has recently been shown in anesthetized cats that excitation and inhibition onto motoneurons is balanced in a "push-pull" fashion when the synaptic input comes from proprioceptive feedback, which is induced externally by stretched muscles (Johnson et al., 2012). In the present study, we address gain modulation when the synaptic input is provided primarily by a central pattern generator with little or no proprioceptive feedback. It is relevant to note that inhibitory feedback via Renshaw interneurons is unlikely to be important in the turtle since motoneuron axon collaterals have not been reported (Ruigrok et al., 1984). Recurrent connection within this network could explain the balanced excitation/inhibition input to motoneurons (Petersen et al., 2014), though the connectivity is largely unknown. The simplest network motif that could explain balanced excitation/inhibition is feedforward excitation/inhibition within the spinal premotor circuit, which has been reported (Parker, 2003). The most common pattern of evoked synaptic input to cat lumbar motoneurons has been found to be a sequential mixture of excitation/inhibition when activating pathways from mesencephalic locomotor regions in the midbrain (Noga et al., 2003), which also indicates the existence of such a feedforward excitation/inhibition motif. Generally, simple circuitries with recurrent feedforward/feedback connections among the premotor neurons, where a fraction projects to the motoneurons, could also explain the balanced excitatory and inhibitory input to motoneurons.

\section{Precision of scratching movement}

In the present study we use the scratching behavior of turtles to address gain modulation of motoneurons. The specific motor behavior is referred to as "pocket scratching" (Stein, 2005). Here, the knee is rubbing against the rostral pocket region between the carapace and the hindlimb attachment, which consists mainly of soft skin. This skin has high sensitivity such that the motor response can be adjusted to carefully direct the knee to the specific location of nuisance tactile stimulation. In cyclic movement, the knee is first moved forward to rub against the location, referred to as "the prerub phase," then retracted back during the "postrub phase" to restart the cycle (Field et al., 1997). In the present study we address gain modulation of motoneurons belonging to the hip flexors, which have to exert a force of high amplitude and precision during the prerub and rub phases. This is contrary to the hip extensors, which are active in the postrub phase, where they retract the limb ballistically without a particular target. The movement in the postrub phase has high variability, whereas the prerub and rub phases have low variability (Mortin et al., 1985). Therefore the motor control of hip flexors are expected to require higher accuracy than the hip extensors, and therefore suitable gain modulation of the hip flexor motoneurons is likely more critical.

\section{Experimental limitations}

The preparation used in this study made it possible to estimate motoneuron properties in an in vivo-like situation (Keifer and Stein, 1983). The estimation of gain was based on two approximations. First, the current injections are a valid proxy for synaptic input. Synaptic currents are induced by changes in membrane conductance, whereas injected current through an electrode is not associated with any change in membrane conductance. Nevertheless, the difference between synaptic current and injected current is minor when the injected current is small compared with the total ongoing synaptic current. The ongoing synaptic currents are quite large in turtle spinal neurons during motor activity, since their conductance often increases several-fold (Alaburda et al., 2005; Berg et al., 2007). Second, the variability of the scratch reflex is small from trial to trial compared with the variability from scratch cycle to scratch cycle in each trial. If the approximation of small trial-to-trial variability does not apply, it would be harder to estimate the gain and establish a correlation with the muscular force. Despite the potential shortcomings of these approximations, a significant and positive correlation between gain and force was found, which suggests that the gain modulating effect would be even more pronounced for the true IO function and for larger force applications.

\section{References}

Alaburda A, Hounsgaard J (2003) Metabotropic modulation of motoneurons by scratch-like spinal network activity. J Neurosci 23:8625-8629. Medline

Alaburda A, Russo R, MacAulay N, Hounsgaard J (2005) Periodic highconductance states in spinal neurons during scratch-like network activity in adult turtles. J Neurosci 25:6316-6321. CrossRef Medline

Berg RW, Alaburda A, Hounsgaard J (2007) Balanced inhibition and excitation drive spike activity in spinal half-centers. Science 315:390-393. CrossRef Medline

Berg RW, Ditlevsen S, Hounsgaard J (2008) Intense synaptic activity en- 
hances temporal resolution in spinal motoneurons. PLoS One 3:e3218. CrossRef Medline

Berkowitz A, Stein PS (1994) Activity of descending propriospinal axons in the turtle hindlimb enlargement during two forms of fictive scratching: broad tuning to regions of the body surface. J Neurosci 14:5089-5104. Medline

Burke RE (1981) Motor units: anatomy, physiology, and functional organization. In: Handbook of physiology: the nervous system (Brooks VB, Brookhart JM, eds), pp 345-422. Bethesda, MD: American Physiological Society.

Carandini M, Heeger DJ (2012) Normalization as a canonical neural computation. Nat Rev Neurosci 13:51-62. CrossRef Medline

Chance FS, Abbott LF, Reyes AD (2002) Gain modulation from background synaptic input. Neuron 35:773-782. CrossRef Medline

de Almeida AT, Kirkwood PA (2010) Multiple phases of excitation and inhibition in central respiratory drive potentials of thoracic motoneurones in the rat. J Physiol 588:2731-2744. CrossRef Medline

Dideriksen JL, Negro F, Enoka RM, Farina D (2012) Motor unit recruitment strategies and muscle properties determine the influence of synaptic noise on force steadiness. J Neurophysiol 107:3357-3369. CrossRef Medline

Enoka RM, Fuglevand AJ (2001) Motor unit physiology: some unresolved issues. Muscle Nerve 24:4-17. CrossRef Medline

Faisal AA, Selen LP, Wolpert DM (2008) Noise in the nervous system. Nat Rev Neurosci 9:292-303. CrossRef Medline

Feinstein B, Lindegard B, Nyman E, Wohlfart G (1955) Morphologic studies of motor units in normal human muscles. Acta Anatomica 23:127142. CrossRef Medline

Field EC, Stein PS (1997) Spinal cord coordination of hindlimb movements in the turtle: intralimb temporal relationships during scratching and swimming. J Neurophysiol 78:1394-1403. Medline

Fuglevand AJ, Winter DA, Patla AE (1993) Models of recruitment and rate coding organization in motor-unit pools. J Neurophysiol 70:2470-2488. Medline

Garnett RA, O’Donovan MJ, Stephens JA, Taylor A (1979) Motor unit organization of human medial gastrocnemius. J Physiol 287:33-43. CrossRef Medline

Guimaraes AC, Herzog W, Hulliger M, Zhang YT, Day S (1994) EMG-force relationship of the cat soleus muscle studied with distributed and nonperiodic stimulation of ventral root filaments. J Exp Biol 186:75-93. Medline

Guzulaitis R, Alaburda A, Hounsgaard J (2014) Dense distributed processing in a hindlimb scratch motor network. J Neurosci 34:10756-10764. CrossRef Medline

Hansel D, van Vreeswijk C (2002) How noise contributes to contrast invariance of orientation tuning in cat visual cortex. J Neurosci 22:5118-5128. Medline

Harris CM, Wolpert DM (1998) Signal-dependent noise determines motor planning. Nature 394:780-784. CrossRef Medline

Hatze H (1979) A teleological explanation of Weber's law and the motor unit size law. Bulletin of Mathematical Biology 41:407-425. CrossRef Medline

Heckman CJ, Mottram C, Quinlan K, Theiss R, Schuster J (2009) Motoneuron excitability: the importance of neuromodulatory inputs. Clin Neurophysiol 120:2040-2054. CrossRef Medline

Henneman E, Mendell L (1981) Functional organization of motoneuron pool and its inputs. In: Handbook of physiology: the nervous system (Brooks VB, Brookhart JM, eds), pp 423-458. Bethesda, MD: American Physiological Society.

Hô N, Destexhe A (2000) Synaptic background activity enhances the responsiveness of neocortical pyramidal neurons. J Neurophysiol 84:14881496. Medline

Hounsgaard J, Kiehn O (1989) Serotonin-induced bistability of turtle motoneurones caused by a nifedipine-sensitive calcium plateau potential. J Physiol 414:265-282. Medline

Hultborn H, Lindström S, Wigström H (1979) On the function of recurrent inhibition in the spinal cord. Exp Brain Res 37:399-403. Medline

Hultborn H, Denton ME, Wienecke J, Nielsen JB (2003) Variable amplification of synaptic input to cat spinal motoneurones by dendritic persistent inward current. J Physiol 552:945-952. CrossRef Medline

Jahn P, Berg RW, Hounsgaard J, Ditlevsen S (2011) Motoneuron mem- brane potentials follow a time inhomogeneous jump diffusion process. J Comput Neurosci 31:563-579. CrossRef Medline

Johnson MD, Heckman CJ (2014) Gain control mechanisms in spinal motoneurons. Front Neural Circuits 8:81. CrossRef Medline

Johnson MD, Hyngstrom AS, Manuel M, Heckman CJ (2012) Push-pull control of motor output. J Neurosci 32:4592-4599. CrossRef Medline

Jones KE, Hamilton AF, Wolpert DM (2002) Sources of signal-dependent noise during isometric force production. J Neurophysiol 88:1533-1544. Medline

Keifer J, Stein PS (1983) In vitro motor program for the rostral scratch reflex generated by the turtle spinal cord. Brain Res 266:148-151. CrossRef Medline

Kernell D, Hultborn H (1990) Synaptic effects on recruitment gain: a mechanism of importance for the input-output relations of motoneurone pools? Brain Res 507:176-179. CrossRef Medline

Kolind J, Hounsgaard J, Berg RW (2012) Opposing effects of intrinsic conductance and correlated synaptic input on Vm-fluctuations during network activity. Front Comput Neurosci 6:40. CrossRef Medline

Mendell LM (2005) The size principle: a rule describing the recruitment of motoneurons. J Neurophysiol 93:3024-3026. CrossRef Medline

Miles GB, Hartley R, Todd AJ, Brownstone RM (2007) Spinal cholinergic interneurons regulate the excitability of motoneurons during locomotion. Proc Natl Acad Sci U S A 104:2448-2453. CrossRef Medline

Miller KD, Troyer TW (2002) Neural noise can explain expansive, powerlaw nonlinearities in neural response functions. J Neurophysiol 87:653659. Medline

Milner-Brown HS, Stein RB, Yemm R (1973) The orderly recruitment of human motor units during voluntary isometric contractions. J Physiol 230:359-370. CrossRef Medline

Mitchell SJ, Silver RA (2003) Shunting inhibition modulates neuronal gain during synaptic excitation. Neuron 38:433-445. CrossRef Medline

Mortin LI, Keifer J, Stein PS (1985) Three forms of the scratch reflex in the spinal turtle: movement analyses. J Neurophysiol 53:1501-1516. Medline

Murphy BK, Miller KD (2003) Multiplicative gain changes are induced by excitation or inhibition alone. J Neurosci 23:10040-10051. Medline

Noga BR, Kriellaars DJ, Brownstone RM, Jordan LM (2003) Mechanism for activation of locomotor centers in the spinal cord by stimulation of the mesencephalic locomotor region. J Neurophysiol 90:1464-1478. CrossRef Medline

Parker D (2003) Activity-dependent feedforward inhibition modulates synaptic transmission in a spinal locomotor network. J Neurosci 23:1108511093. Medline

Parkis MA, Dong X, Feldman JL, Funk GD (1999) Concurrent inhibition and excitation of phrenic motoneurons during inspiration: phase-specific control of excitability. J Neurosci 19:2368-2380. Medline

Perrier JF, Hounsgaard J (2000) Development and regulation of response properties in spinal cord motoneurons. Brain Res Bull 53:529-535. CrossRef Medline

Petersen PC, Vestergaard M, Jensen KH, Berg RW (2014) Premotor spinal network with balanced excitation and inhibition during motor patterns has high resilience to structural division. J Neurosci 34:2774-2784. CrossRef Medline

Polack PO, Friedman J, Golshani P (2013) Cellular mechanisms of brain state-dependent gain modulation in visual cortex. Nat Neurosci 16:13311339. CrossRef Medline

Powers RK, Elbasiouny SM, Rymer WZ, Heckman CJ (2012) Contribution of intrinsic properties and synaptic inputs to motoneuron discharge patterns: a simulation study. J Neurophysiol 107:808-823. CrossRef Medline

Rabinowitz NC, Willmore BD, Schnupp JW, King AJ (2011) Contrast gain control in auditory cortex. Neuron 70:1178-1191. CrossRef Medline

Rekling JC, Funk GD, Bayliss DA, Dong XW, Feldman JL (2000) Synaptic control of motoneuronal excitability. Physiol Rev 80:767-852. Medline

Ruigrok TJ, Crowe A, ten Donkelaar HJ (1984) Morphology of lumbar motoneurons innervating hindlimb muscles in the turtle Pseudemys scrìpta elegans: an intracellular horseradish peroxidase study. J Comp Neurol 230:413-425. CrossRef Medline

Saywell SA, Feldman JL (2004) Dynamic interactions of excitatory and inhibitory inputs in hypoglossal motoneurones: respiratory phasing and modulation by PKA. J Physiol 554:879-889. CrossRef Medline

Senn W, Wyler K, Clamann HP, Kleinle J, Lüscher, HR, Müller L (1997) Size principle and information theory. Biol Cybern 76:11-22. CrossRef Medline

Silver RA (2010) Neuronal arithmetic. Nat Rev Neurosci 11:474-489. CrossRef Medline 
Stein PS (2005) Neuronal control of turtle hindlimb motor rhythms. J Comp Physiol A Neuroethol Sens Neural Behav Physiol 191:213-229. CrossRef Medline

Stein RB, Gossen ER, Jones KE (2005) Neuronal variability: noise or part of the signal? Nature Rev Neurosci 6:389-397. Medline

Takei T, Seki K (2013) Spinal premotor interneurons mediate dynamic and static motor commands for precision grip in monkeys. J Neurosci 33: 8850 -8860. CrossRef Medline

Todorov E (2004) Optimality principles in sensorimotor control. Nat Neurosci 7:907-915. CrossRef Medline

Walløe S, Nissen UV, Berg RW, Hounsgaard J, Pakkenberg B (2011) Stereological estimate of the total number of neurons in spinal segment D9 of the red-eared turtle. J Neurosci 31:2431-2435. CrossRef Medline

Watanabe RN, Magalhães FH, Elias LA, Chaud VM, Mello EM, Kohn AF
(2013) Influences of premotoneuronal command statistics on the scaling of motor output variability during isometric plantar flexion. J Neurophysiol 110:2592-2606. CrossRef Medline

Wei K, Glaser JI, Deng L, Thompson CK, Stevenson IH, Wang Q, Hornby TG, Heckman CJ, Kording KP (2014) Serotonin affects movement gain control in the spinal cord. J Neurosci 34:12690-12700. CrossRef Medline

Wilson NR, Runyan CA, Wang FL, Sur M (2012) Division and subtraction by distinct cortical inhibitory networks in vivo. Nature 488:343-348. CrossRef Medline

Windhorst U (1996) On the role of recurrent inhibitory feedback in motor control. Prog Neurobiol 49:517-587. CrossRef Medline

Wu G, Perlmutter SI (2013) Sensitivity of spinal neurons to GABA and glycine during voluntary movement in behaving monkeys. J Neurophysiol 109:193-201. CrossRef Medline 